\title{
Research on the Comprehensible Output of Peer Interaction in College English Class
}

\author{
Yufeng Wang \\ School of Foreign Languages \\ Huanghe Science and Technology College \\ Zhengzhou, China 450063
}

\begin{abstract}
This paper firstly presents the function of classroom interaction in college English class from the aspects of theoretical basis and practical research. Secondly, it's the direct relationship between students. So, it's necessary and important for teachers to imply the peer interaction into classroom teaching. Thirdly, the author analyzes the validity of peer interaction in understandable output. Finally, this paper ends with highlighting the significance of peer interaction.
\end{abstract}

Keywords—peer interaction; understandable output

\section{INTRODUCTION}

The emphasis on the cultivation of students' language ability is that the teachers are found to be the center of the traditional teaching mode in English Teaching. Under the circumstance that large classes are not suitable, there exist a variety of problems: students are passive in learning, and it is difficult to pass feedbacks, the opportunities of oral practice reduce. Facing these challenges, teachers should work as the center of cooperative learning. It is the center of traditional English teaching.

Interaction teaching in classroom is the interaction between teachers and students based on the teaching content and it is the face-to-face interaction between teachers and students. It is a language communication activity. For students, it is an opportunity to learn and practice language. Since 1980s, the study of classroom interaction has always been the research hotspot in the field of foreign language. Since the beginning of this century, domestic classroom interaction research has attracted much attention of foreign language teachers and researchers. Compared with the interaction between teachers and students, the interaction among students provides more opportunities for learners to use target language, reduces the learner's anxiety, and makes them confident (Davis, 1997). Besides, peer interaction makes students in the group to participate more in the meaningful exchange.

\section{PEER INTERACTION}

Peer feedback is another style of feedback; it is different

In the central plains economic zone the constructive study of language services under the background of internationalization; the general project of humanities and social science from Henan province, department of education (No: 2016-qn-167). to teacher's feedback. As the name suggests, it is the mutual response between the students and the evaluation. Constructionist learning theory, interaction theory, the recent development zone theory, effective filters hypothesis, etc. It provides a strong theoretical support for the "peer feedback" from various angles.

Peer interaction is a kind of communicative activity which takes place among learners. In this process, the participations of teachers are little. It includes cooperation and cooperative learning, peer guidance and other forms in helping others (Philp el al. 2014). The characteristics of peer interaction are reflected among the participants to work together for a common goal. Peer interaction is involved in multi-parts interactions for its involving at least two participants.

The symmetry of peer interaction is that learners are given equal rights and have similar knowledge and experience in peer relationships. In the process of peer interaction teaching, the students' vocabulary is increasing. Grammar will be more proficient than ever before. The ability of listening and speaking has been greatly improved. What is more important, students' awareness of autonomous learning is obviously enhanced. Through solving one problem after another they have realized their own progress and ability, and meet the need of desire for self realization and successful psychological value, which stimulates the desire for further study.

The role of peer assisted learning in College English Teaching:

- All students can study in equal status, and everyone has the opportunity to become their own teacher. Students can get the opportunity to show themselves, and it is advantageous to set up their self-confidence. In the peer learning process, each member of the team's knowledge system will become clearer and perfect through mutual help, and they can find some shortcomings and deficiencies on the other side.

- It can mobilize the enthusiasm of the students and enhance their learning motivation. Peer support of cooperative learning model through the students into groups, and a large classroom for a number of small classroom increasing the interaction between students 
are conducive to stimulating students' interests in learning. This mutual activity will make the whole class lively and achieve a good teaching effect.

- It can create more language practice opportunities. Students' mastery of language knowledge requires a lot of repeated practice, and the practical activities can be arranged in the limited time of the classroom. However, it is difficult to meet the requirements of many students. Peer mutual learning can provide two levels of interactive opportunities: one is the teacher and the student; the other is between the students and students. In this way, students will have the opportunity to expand the language, and ensure the efficiency of classroom teaching.

- It is conducive to the cultivation of student's team spirit and independent consciousness. According to the communication theory, the learning process is a cognitive process and emotional process, one can understand limited things, and when we put their knowledge of things together, each person in this group will grasp more comprehensive and rich knowledge. Peer support learning is in this way to make the students involved in the more comprehensive language knowledge.

\section{PEER INTERACTION AND COOPERATIVE LEARNING}

The application of cooperative learning strategy is mainly the operation of the cognitive development theory, the cognitive elaboration theory and the constructivism theory. Cognitive development theory believes that social expertise, such as language, values, rules, ethics and symbolic system (text and symbols), only in the interaction with the Chinese side to learn.

Thinking and cooperation are the individuals' thinking activities, and external cooperation is one of the two sides. In the cooperative learning process, encouraging thinking and discussion firstly are helpful to the development of highlevel cognitive. Cooperative learning group is a kind of teaching activity in teaching organization form, and the basic principle of packet diversity of team members must have the language levels, learning achievement, gender, personality and learning style.

Second, the interaction and cooperation among peers are emphasized, but each member of the class is responsible for the learning tasks, and the group also has individual responsibility for the whole class. Third, cooperative learning is the common goal scheduled and the strategy of organizing cooperative language learning activities.

- Team members are to complete the task of group learning task. This kind of cooperative language learning is the closest to the traditional teaching method, which is suitable for the teaching content in the teaching material. Teachers put forward the need to learn the content of the target, and the group started to learn and discuss. Helping each other makes each member understand the teaching content of the target. The teacher is required to report to the class by asking teams to collect feedback and give help or correction if necessary.

- The different parts of the group learning tasks are assigned by the team members. This form of cooperative learning and the common place of the first kind of learning content are mostly from the teaching material or the designated teacher. The difference is that each member of the team completes the different parts of the common task, and the completion of the members of the group is an indispensable part of the task. The group may its own divisions of labor or by the teacher according to the language level to carry on the division of labor. When the members complete their own tasks together, discuss the results, and then solve the problem or oral discourse and other forms as the ultimate goal of the completion of the task.

- All members of the group should complete the different parts of the class task. This form of cooperative learning is the combination of two forms. Teachers put forward the goal of learning content; it will be composed into the group. Because the task of each group is different, this forms the information gap. When the teams are reporting on their own tasks, the rest of the group can learn from it or improve it.

- The team should complete their own choice of learning tasks. This form of cooperative learning can be seen as an extension of forms. The key difference is that the group can choose their own learning content and methods. In the range of selected learning tasks, each group has its own division of labor, and the formation of its own mechanism to ensure the completion of the task of control and integration.

The cooperative language activities provide students with the following advantages:

- The students are endowed with autonomy to take responsibility for their own learning, and promote the learning motivation.

- The students' concept of language learning can be changed, which is beneficial to the acquisition and improvement of English communicative competence.

- The students have the ability to gradually solve problems and providing innovative space.

- Students learn to find their own problems in the process of learning, and correct the problem through evaluation and self-evaluation.

- In the process of cooperative learning, students learn social skills, help others and accept other people's assistance, tolerate differences and maintain a friendly and harmonious atmosphere. 


\section{PEER INTERACTION IN UNDERSTANDABLE OUTPUT}

Cooperative learning promotes comprehensible input from three aspects. First, as another source of input, they provide an understandable input that may be more interesting. Second, the easy language of the peer atmosphere is more suitable for language input. Finally, the input from the companion contains many information, interpretation, elaboration and are more comprehensible.

When learners have the opportunity to consult the content they hear in order to clarify the meaning of the exchange of interaction, which can make the input of language be more understandable. Peer interaction, whether it is a common verification or seeking explanation, it can promote second language learning, because these two activities provide learners with comprehensible input (Long 1996). Just as Pica said, participants modify the way they express their meaning in the negotiating process to overcome the difficulties of communication. (Such as through repetition, restructuring or language reports), this negotiation interaction can promote the mutual understanding between learners. Besides, it can provide ways for learners to understand the target language, pay attention to the meaning of the target language, and provide the learners with an opportunity to try to use the language at the same time. Peer interaction makes the learners' attention focus on the meaning of language forms in the context and leads them to make more complex or more accurate target language form.

Meanwhile, Swain's (1985) Output hypothesis says, only input is not enough. Comprehensible output will promote language acquisition, in the process of output, creating opportunities for learners to pay attention to the interlanguage and the forms of the target language test their hypothesis of the target language. Rethinking their language to facilitate language acquisition when learners pay attention to the gap between the medium and the target language. They will use the knowledge of second language to adjust the output and produce more accurate and complex language.

In the course of interaction between teachers and students, adjusted by the teacher to provide the appropriate help and meet the requirements of the students. This form of help is called a "bracket" in the cooperative learning of peer interaction, non-experts can also provide assistance to each other. Peer interaction in the classroom works as the dual role of experts and novices and it helps each other to solve problems. A good peer can give his peer effective help. There are studies showing that the scaffold is a two-way but one. Learners in a lower level also provide support for learners in higher level. In the process of peer interaction, the learners use the target language to communicate with each other and provide support to them to reflect the language forms of their use and adjust or modify the output of the language (Mackey, 2012).

And Swain's output hypothesis (Swain, 1985: 235-253) admits the necessity of comprehensible input, and puts forward the importance of output and its four basic functions in the two language acquisition. In addition, the interaction of Long (1985:377-393) hypothesis points out that the interaction in the cooperative learning can promote the two language acquisition under certain conditions.

The survey to "peer feedback" teaching practice brings many inspirations: (1). in the activity design, activity time should not be too long to refine the content of activities and improve the taste and practicality taking diversity into account. The crew is configured to harmonious relationship, strong ability or equivalent ideal condition. (2). In the trigger strategy, the types of activities is the "role play", "participate in the teaching design", "group discussion", "group competition", "speech" and other forms of "debate", and "teaching practice" can push the implementation of high grade stage. The learning evaluation among students is a useful attempt to promote students' positive thinking and cooperative learning, and expect further research to improve its effectiveness. (3). Reflecting the investigation in the feedback content though "peer feedback" on the content of discourse, but the majority of respondents to the language form error correction needs, so it is necessary to encourage students to use the appropriate feedback strategy, and correct it timely. (4). In the direction of the theory of feedback strategy, appropriate theoretical introduction can make students understand the purpose and methods of the activities, so that the interaction is more targeted and scientific. In strategy application, students should be encouraged to overcome inertia, cultivate the habit of correcting mistakes, correct errors, and improve the quality of feedback by consulting and dictionary.

In conclusion, this investigation objectively records the students to "peers feedback" activity design, trigger strategy, feedback content and strategy guidance problems views and suggestions, and put forward the solutions for specific problems, expect to bring fresh breath for English teaching and lead to innovation research.

Evidence shows that in the task-based interaction, learners will make meaningful negotiation. And it provides various types of feedback to each other. Although there is not many meaningful negotiations between learners. But they will be able to correct their own words without being pushed. Peer interaction enables learners to produce comprehensible output in the process of completing cooperative tasks. Learners will use both cognitive and social interaction in cooperative dialogue to construct knowledge and make communication easier to be understood.

\section{CONCLUSION}

Peer interaction teaching makes the classroom atmosphere become more and more active, and it helps students learn initiatively and improve their abilities of listening, speaking, reading and writing greatly. Awareness of cooperation and communication skills are also greatly enhanced as well as improving the efficiency of classroom learning. Interactive teaching process can make it easier to communicate with the output of comprehensible language output. 


\section{REFERENCES}

[1] Foster, p. 1998. A classroom perspective on the negotiation of meaning. Applied Linguistics, (1):1-23.

[2] Gass. S.1997. Input, Interaction, and the Second Language Learner [M]. Mahwah, N.J.: Lawrence Erlbaum Associates.

[3] Johnson, D., R. Johnson \& E. Holubec. 1994. Cooperative Learning in the Classroom [M]. Alexandria, VA: Association for Supervision and Curriculum Development.

[4] Johnson, D. 1986. Reaching out ( ${ }^{\text {rd }}$ edition) [M]. Englewood, N.J.: Prentice Hall.

[5] Krashen, S. 1981. Second Language Acquisition and Second Language Learning [M]. Oxford: Pergamon.

[6] Pica, T. 2013. From input, output and comprehension to negotiation, evidence and attention: An overview of theory and research on learner interaction and SLA[A]. Contemporary Approaches to Second Language Acquisition [C]. Amsterdam: John Benjamins.

[7] Philp, J., R. Adams \& N. Iwashita. 2014. Peer Interaction and Second Language Learning [M]. New York: Routledge.

[8] Swain, M\&S. Lapkin.1998. Interaction and second language learning: Two adolescent French immersion students working together [J]. The Modern Language Journal, (3). 